\title{
Estudo das Propriedades Mecânicas de um Composto de PVC Modificado com Fibras de Bananeira
}

\author{
Palova S. Balzer, Lawrence L. Vicente, Ricardo Briesemeister, Daniela Becker \\ Instituto Superior Tupy, Sociesc \\ Valdir Soldi \\ Departamento de Química, UFSC \\ Antonio Rodolfo Jr., Murilo B. Feltran \\ Braskem S.A.
}

\begin{abstract}
Resumo: Neste trabalho foram avaliadas as propriedades de compósitos de poli (cloreto de vinila) - PVC rígido com adição de fibras de bananeira. As fibras foram extraídas do pseudocaule da bananeira e incorporadas nas proporções de $5,10 \mathrm{e}$ $20 \%$ em volume em um composto de PVC rígido pelo processo de extrusão. Para a obtenção dos corpos de prova utilizados na caracterização das formulações foi utilizado o processo de injeção. A utilização de fibras extraídas do pseudocaule da bananeira, tratadas manualmente em um processo simples desenvolvido na SOCIESC, mostra-se como alternativa viável na forma de fibra de reforço para a produção de compósitos de PVC rígido, tendo mostrado aumento da resistência à tração, discreta redução no alongamento na ruptura e aumento da resistência ao impacto, bem como redução, mesmo que discreta, no peso específico do compósito resultante, potencializando a obtenção de componentes com melhor desempenho mecânico e menor peso.
\end{abstract}

Palavras-chave: Poli(cloreto de vinila), PVC, fibra de bananeira, compósitos.

\section{Study of the Mechanical Properties of PVC/Banana Fiber Composites}

Abstract: Mechanical properties (tensile and impact resistance), specific weight and phase morphology of PVC/banana tree fiber composites were evaluated in this paper. The fibers were extracted from de pseudostem of the banana tree and mixed with a rigid PVC compound in the proportions of 5, 10 and $20 \%$ in volume by the extrusion process. Specimens were obtained by injection molding. The composites showed improvement of the impact and tensile properties, reduction of the specific weight, making possible the production of final products.

Keywords: Poly(vinyl cloride), PVC, banana tree fiber, composites.

\section{Introdução}

Atualmente a constante busca pela utilização de fibras para reforço de materiais poliméricos tem encontrado diversas tendências, entre elas as fibras naturais, que além de reforçar o polímero, são biodegradáveis, possuem baixo custo, são leves (devido à baixa densidade destas fibras) e não possuem característica abrasiva (causam menos desgaste à peça e facilitam o processo de moldagem). As fibras naturais são provenientes de fontes renováveis e possuem propriedades mecânicas que podem aumentar as propriedades dos polímeros com elas aditivados ${ }^{[1-3]}$. Entre as fibras naturais mais usadas destacam-se as fibras de sisal, coco, curauá, bambu, pinus, bananeira, entre outras.

As fibras de bananeira se destacam por ser de cultivo fácil em países tropicais. O pseudocaule, após oferecer o fru- to, pode proliferar fungos com difícil controle de tratamento, devido à alta umidade incidente nas plantações. Sendo assim, a extração do pseudocaule das bananeiras pode ser uma alternativa de renda interessante para a mão de obra rural, além de poder ser uma alternativa viável para confecção de artesanatos e reforço de resinas termoplásticas ${ }^{[4-6]}$.

$\mathrm{O}$ emprego de fibras naturais como reforços em matrizes poliméricas, tanto termofixas como termoplásticas, vem apresentando vantagens em relação às propriedades mecânicas de tração e peso específico ${ }^{[7-9]}$.

Dentre as resinas termoplásticas viáveis para o emprego de fibras de bananeira destaca-se a resina de poli(cloreto de vinila) - PVC por sua versatilidade em relação a sua formulação, pois há a necessidade da incorporação de aditivos durante o seu processamento, tornando-a adaptável a múltiplas aplicações ${ }^{[10]}$.

Autor para correspondência: Palova S. Balzer, Instituto Superior Tupy, Sociesc, R. Albano Schmidt 3333, CEP 89227-700, Joinville, SC, Brasil. E-mail:palova@sociesc.com.br 
Este trabalho tem como objetivos obter e avaliar compósitos de PVC rígido com fibras de bananeira nas proporções de 5, 10 e $20 \%$ em volume de fibra, analisando seus efeitos nas propriedades mecânicas de tração e impacto, bem como peso específico e características morfológicas.

\section{Experimental}

\section{Obtenção do composto de PVC}

A formulação do composto de PVC rígido utilizado foi com base no trabalho de Balzer e colaboradore ${ }^{[11]}$, sendo empregada a resina de PVC Norvic ${ }^{\circledR}$ SP 1000 fornecido pela Braskem $\mathrm{S} / \mathrm{A}$, com valor K 65. A mistura do PVC com os aditivos (Tabela 1) foi realizada em um misturador intensivo (Hansen Máquinas e Equipamentos S/A tipo H). No primeiro estágio de mistura atingiu-se $90{ }^{\circ} \mathrm{C}$, sendo o composto liberado para o vaso de resfriamento, permanecendo por 10 minutos e retirado em seguida. Os aditivos empregados para a obtenção do composto estão descritos na Tabela 1 juntamente com a formulação empregada em gramas e em pcr (partes por cem partes de resina).

\section{Obtenção das fibras de bananeira}

As fibras de bananeira foram extraídas, do pseudocaule de bananeiras de qualidade prata, manualmente e na forma de tiras previamente lavadas em solução aquosa de água sanitária a $10 \%$ e secas em estufa a $60^{\circ} \mathrm{C}$. A Figura 1 mostra as fibras após serem secas.

Tabela 1. Formulação empregada para a obtenção do composto de PVC rígido

\begin{tabular}{|c|c|c|c|}
\hline Material & $\begin{array}{l}\text { Teor } \\
\text { (pcr) }\end{array}$ & $\begin{array}{c}\text { Quantidade } \\
\text { (kg) }\end{array}$ & $\begin{array}{c}\text { Função na } \\
\text { formulação }\end{array}$ \\
\hline $\begin{array}{c}\text { PVC } \\
\text { (Norvic }^{\circledR} \text { SP 1000) }\end{array}$ & 100 & 25 & $\begin{array}{c}\text { Matriz } \\
\text { polimérica }\end{array}$ \\
\hline Naftomix XC 8101 & 3,6 & 0,900 & $\begin{array}{l}\text { Estabilizante } \\
\text { térmico }\end{array}$ \\
\hline Comarlub 05 & 0,2 & 0,050 & $\begin{array}{l}\text { Lubrificante } \\
\text { interno }\end{array}$ \\
\hline Estearina & 0,5 & 0,125 & $\begin{array}{l}\text { Lubrificante } \\
\text { externo }\end{array}$ \\
\hline Paraloid K-120 & 0,5 & 0,125 & $\begin{array}{c}\text { Modificador } \\
\text { de fluxo }\end{array}$ \\
\hline
\end{tabular}

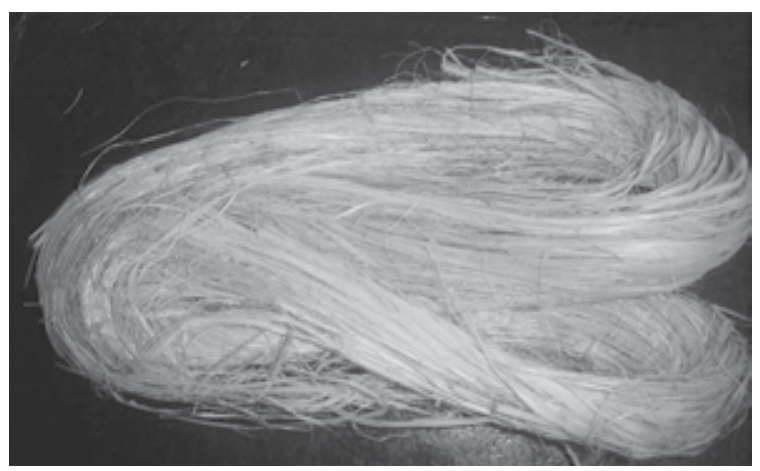

Figura 1. Fibras extraídas do pseudocaule da bananeira secas ao ar.
Após a secagem as fibras foram desfiadas e cortadas com comprimento médio de $10 \mathrm{~mm}$. A espessura média das fibras de bananeira utilizadas neste trabalho foi determinada no microscópio de medição Carl Zeiss Jena GWM - DC e apresentaram espessura média de 0,04 $\mathrm{mm}$.

\section{Obtenção dos compósitos de PVC rígido com fibras de bananeira}

As misturas foram preparadas em uma extrusora monorosca Ciola com L/D 25/1. A temperatura de processamento por extrusão variou de 160 a $180{ }^{\circ} \mathrm{C}$, com rotação da rosca de $60 \mathrm{rpm}$. Foram preparados compósitos com 5, 10 e 20\% em volume de fibras de bananeira. Os compósitos, após extrudados, foram resfriados ao ar e moídos em um moinho de facas Primotécnica modelo P 2001.

\section{Obtenção dos corpos de prova}

Para a obtenção dos corpos de prova foi utilizada uma injetora Battenfeld HB 750/3115 CD. Primeiramente foi injetada a formulação de PVC rígido puro para determinação dos parâmetros básicos de processamento do equipamento, e em seguida, foram obtidos os corpos de prova dos compósitos. Foi utilizado um perfil de temperatura variando de 130 a $160{ }^{\circ} \mathrm{C}$, pressão de recalque de 60 bar e tempo de resfriamento de 20 segundos (corpos de prova de tração) e 15 segundos (corpos de prova de impacto).

\section{Caracterização das formulações}

A caracterização dos compósitos quanto às propriedades de tração foi realizada em uma máquina universal de ensaios Kratos conforme a norma ISO 527. As propriedades de impacto foram determinadas segundo a norma ISO 180, em um equipamento Microtest e utilizando-se um martelo de 0,5 J.

O peso específico foi determinado através do método por deslocamento de água (pesagem hidrostática) com base na norma ASTM D792. Para isto foi utilizada uma balança Sartorius (0,0001 gramas) e acessórios. Amostras fraturadas no ensaio de impacto foram recobertas com uma fina camada de ouro e observadas em microscópio eletrônico de varredura (MEV) JSM T 300 de forma a avaliar a morfologia dos compósitos.

\section{Resultados e Discussão}

A Tabela 2 apresenta os resultados obtidos a partir dos ensaios de tração, de impacto e de peso específico (média dos resultados obtidos e desvio padrão).

Constatou-se que com o aumento do teor de fibra de bananeira no compósito ocorre um leve decréscimo no peso específico. Isto se deve ao fato do menor peso específico das fibras de bananeira e da porosidade da mesma quando comparado ao composto rígido de PVC.

Na Figura 2 são apresentados os resultados obtidos no ensaio de tração ajustados em função do peso específico dos compósitos, de forma a avaliar a relação resistência/peso. É 
Tabela 2. Resultados obtidos a partir dos ensaios de tração, de impacto e de peso específico das formulações de PVC rígido com e sem adição de fibra de bananeira.

\begin{tabular}{ccccc}
\hline $\begin{array}{c}\text { Teor de fibra de bananeira } \\
(\% \text { volume })\end{array}$ & $\begin{array}{c}\text { Resistência à tração } \\
\left(\mathbf{k g f} / \mathbf{c m}^{2}\right)\end{array}$ & $\begin{array}{c}\text { Deformação na } \\
\text { ruptura }(\boldsymbol{\%})\end{array}$ & $\begin{array}{c}\text { Resistência ao } \\
\text { impacto }\left(\mathbf{k J} / \mathbf{m}^{\mathbf{2}}\right)\end{array}$ & Peso específico $\left(\mathbf{g} / \mathbf{c m}^{\mathbf{3}}\right)$ \\
\hline 0 & $507,1( \pm 9,5)$ & $21,9( \pm 1,3)$ & $1,7( \pm 0,1)$ & $1,3817( \pm 0,0085)$ \\
5 & $502,4( \pm 2,2)$ & $17,2( \pm 1,5)$ & $2,2( \pm 0,2)$ & $1,3716( \pm 0,003)$ \\
10 & $545,9( \pm 4,6)$ & $18,4( \pm 0,5)$ & $2,4( \pm 0,2)$ & $1,3689( \pm 0,0061)$ \\
20 & $525,9( \pm 3,1)$ & $17,0( \pm 1,3)$ & $1,8( \pm 0,1)$ & $1,3533( \pm 0,0037)$ \\
\hline
\end{tabular}

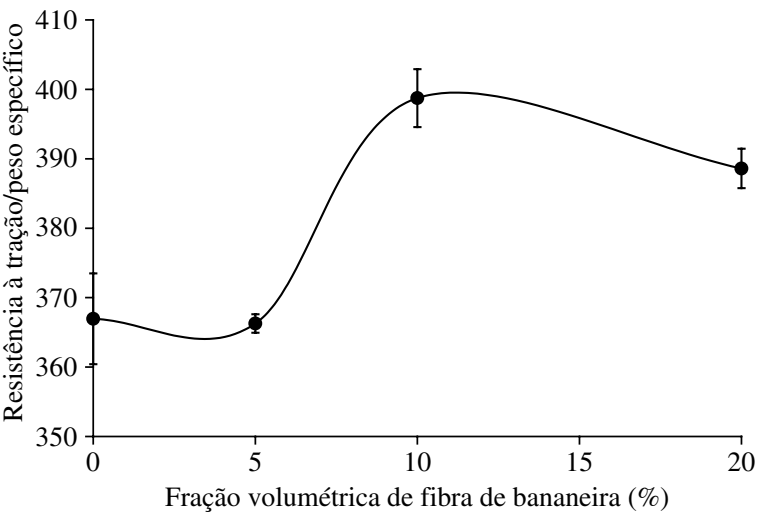

Figura 2. Relação resistência à tração/peso específico dos compósitos de PVC rígido com fibra de bananeira.

possível observar que, com a adição de fibra de bananeira, houve aumento destas propriedades, sendo estes resultados significativos do ponto de vista estatístico conforme evidenciado por análise de variâncias (ANOVA) com intervalo de confiança de $95 \%$. A formulação que apresentou maior alteração foi a com $10 \%$ de fibra, sendo de $8 \%$ o aumento nesta propriedade. Analisando esses dados observa-se que a incorporação da fibra de bananeira no composto de PVC, mesmo sem tratamento das fibras ou adição de compatibilizantes, traz um potencial de reforço ao compósito produzido.

Devido a problemas no equipamento da Sociesc não foi possível avaliar os efeitos da fibra de bananeira no módulo elástico dos compósitos de PVC, motivo pelo qual estes resultados não são apresentados no presente estudo.

A deformação na ruptura reduz-se discretamente com a crescente adição de fibra de bananeira, resultados este esperado para polímeros reforçados. Constatou-se que, com a incorporação das fibras de bananeira no composto de PVC, ocorreu um decréscimo de aproximadamente 22, 16 e $23 \%$ em relação ao composto de PVC puro.

Na Figura 3 são apresentados os resultados obtidos no ensaio de resistência ao impacto, ajustados em função do peso específico dos compósitos. Com a incorporação da fibra percebe-se um aumento aproximado de 28, 43 e $6 \%$, para as formulações com 5, 10 e $20 \%$ de fibras de bananeira, respectivamente, em comparação ao composto de PVC puro, sendo estes resultados significativos do ponto de vista estatístico conforme evidenciado por análise de variâncias (ANOVA) com intervalo de confiança de 95\%. Estes resultados sugerem que a incorporação das fibras no composto de PVC altera a concentração de tensão local ao longo das fibras

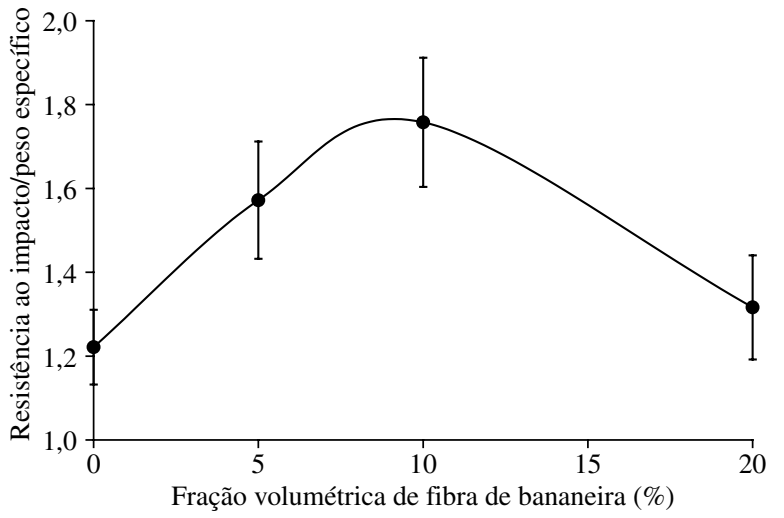

Figura 3. Relação resistência ao impacto/peso específico dos compósitos de PVC rígido com fibra de bananeira.

podendo levar a uma mudança no mecanismo de deformação do compósito ${ }^{[12]}$. Já para a formulação com $20 \%$ de fibra de bananeira este aumento da resistência ao impacto não foi tão significativo (na verdade, insignificante do ponto de vista estatístico conforme teste ANOVA realizado), provavelmente devido à baixa afinidade entre a matriz e o reforço ${ }^{[1]}$, isto comprovado através de microscopia eletrônica de varredura (MEV, Figura 4).

Conforme observado nas micrografias constata-se que a baixa afinidade entre a matriz e a fibra é indicada pela falta de adesão na interface e pelos vazios decorrentes do arrancamento das fibras, sugerindo a necessidade de um tratamento prévio das fibras e/ou adição de um agente compatibilizante, de forma a incrementar a adesão interfacial.

\section{Conclusões}

A utilização de fibras extraídas do pseudocaule da bananeira, tratadas manualmente em um processo simples desenvolvido na Sociesc, mostra-se como alternativa viável na forma de fibra de reforço para a produção de compósitos de PVC rígido.

A incorporação da fibra de bananeira ao PVC produz os efeitos esperados em qualquer sistema polímero/fibra de reforço: aumento da resistência à tração, discreta redução no alongamento na ruptura e aumento da resistência ao impacto. A incorporação desta fibra traz ainda outro efeito positivo: a redução, mesmo que discreta, no peso específico do compósito resultante, potencializando a obtenção de componentes com melhor desempenho mecânico e menor peso. 

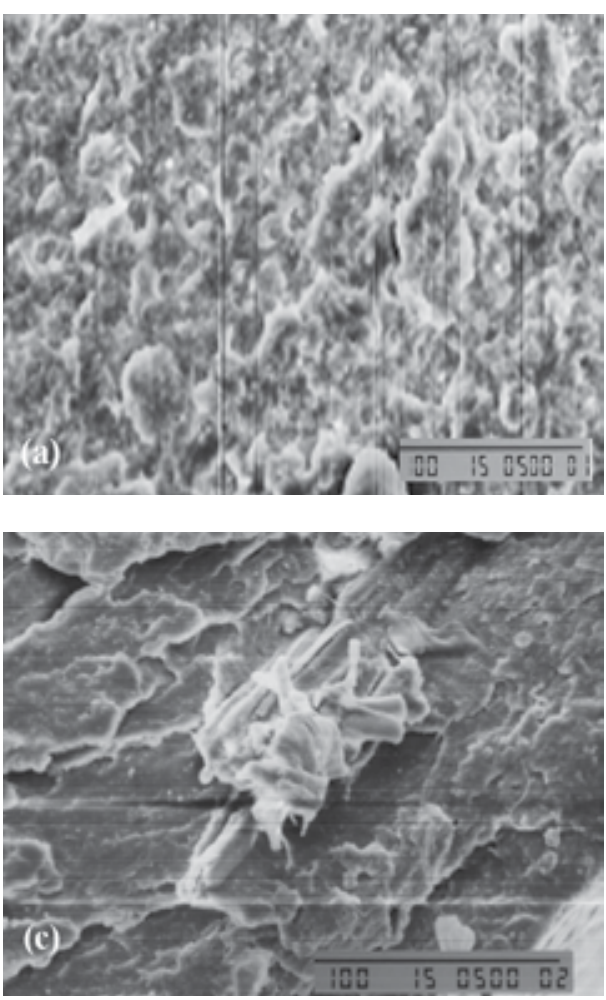
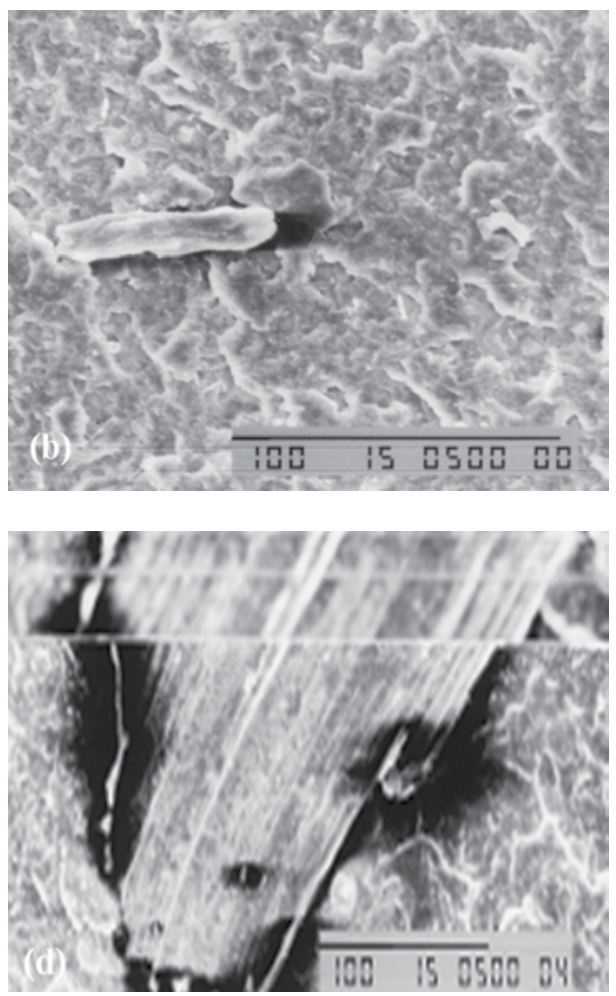

Figura 4. Micrografias eletrônicas de varredura (MEV) da superfície de fratura do composto de PVC com e sem fibras de bananeira com aumento de 500x. a) Composto de PVC puro; b) composto de PVC com 5\% em volume de fibra de bananeira; c) composto de PVC com $10 \%$ em volume de fibra de bananeira; d) composto de PVC com $20 \%$ em volume de fibra de bananeira.

Micrografias eletrônicas de varredura obtidas para as diversas variantes estudadas para o compósito PVC/fibra de bananeira mostram que, apesar dos efeitos de reforçamento obtidos, a transferência de tensões na interface entre a fibra e a matriz polimérica merece estudo mais aprofundado, evidenciado pela pouca adesão nesta interface. Pesquisas relativas ao desenvolvimento de compatibilizantes específicos para o par PVC/fibra de bananeira possam se desdobrar a partir deste estudo inicial, e com a melhora na afinidade química entre a fibra e a matriz polimérica as propriedades deste compósito possam vir a melhorar ainda mais.

\section{Referências Bibliográficas}

1. Rodolfo Jr., A. - "Estudo da processabilidade e das propriedades de PVC reforçado com resíduos de Pinus", Dissertação de Mestrado, Escola Politécnica da Universidade de São Paulo, Brasil (2005).

2. Pothan, L. A. et al. - Composites Science and Technology, 63, p.1231 (2003).

3. Ishizaki, M. H. et al. - Polímeros: Ciência e Tecnologia, 16, p.182 (2006).
4. Sapuan, S. M. et al. - Materials \& Design, 26, p.65 (2006).

5. Fekadu, D.; Ledin, I. - Livestock Production Science, 49, p.249 (1997).

6. Mishra, J. B. et al - Composites Science and Technology, 60, p.1729 (2000).

7. Oksman, K.; Clemons, C. - Journal of Applied Polymer Science, 67, p.1503 (1998).

8. Gomes, A. et al. - JSME International Journal Series, 47, p.541 (2004).

9. Spinacé, A. A. S. et al. - "Termoplásticos reforçados com fibra de curauá processados por extrusão e moldados por injeção", in: Anais do Congresso Plastshow, São Paulo (2006).

10. Rodolfo Jr., A.; Nunes, L. R.; Ormanji, W. - “Tecnologia do PVC", 2. ed., ProEditores Associados, São Paulo (2006).

11. Balzer, P. et al. - Revista do Instituto Superior Tupy, 7, p.58 (2006).

12. Bucknall, C. B. - "Toughned Plastics", Applied Science Publ., Londres (1997). 